\title{
PENGGUNAAN KARTU PERSILANGAN GENETIKA TRIHIBRIDA SEBAGAI MEDIA PEMBELAJARAN BIOLOGI DAPAT MENINGKATKAN HASIL BELAJAR DAN AKTIVITAS SISWA KELAS XII MAN BINJAI
}

\author{
Fauziah \\ Surel: ffauziah71@gmail.com
}

\begin{abstract}
The purpose of this study was to increase student activity in Biology lessons. Based on research and data processing, it was found that the use of the Trihybrid Genetic Crosses card (three different traits) as a Biology learning medium, can improve the learning outcomes of class XII students of Madrasah Aliyah Negeri Binjai in the 2019/2020 school year in Biology lessons on Trihybrid Genetic Crosses (three different traits). ), this can be seen from the calculation of the correlation value in the first cycle between the pre-test to the first daily test of 0.827 with a $t$-test value of 8.333 , and the second cycle between the post-test to the second daily test of 0.943 with a t-test value of 16.075. The use of the Trihybrid Genetic Cross card (three different traits) as a Biology learning medium, can increase the activity of class XII students of Madrasah Aliyah Negeri Binjai in the 2019/2020 school year in Biology lessons on Trihybrid Genetic Crosses (three different traits), this can be seen from the presence students during classroom action research (CAR), from $90 \%$ of the first cycle increased to $95 \%$ and $100 \%$ of the second cycle.
\end{abstract}

Keywords : Trihybrid Genetic Cross Card as Biology Learning Media, Learning Outcomes, Activities

\begin{abstract}
ABSTRAK
Tujuan penelitian ini adalah untuk meningkatkan aktivitas siswa pada pelajaran Biologi. Berdasarkan penelitian dan pengolahan data diperoleh bahwa penggunaan kartu Persilangan Genetika Trihibrida (tiga sifat beda) sebagai media pembelajaran Biologi ini, dapat meningkatkan hasil belajar siswa kelas XII Madrasah Aliyah Negeri Binjai tahun pelajaran 2019/2020 pada pelajaran Biologi tentang Persilangan Genetika Trihibrida (tiga sifat beda), hal ini dapat dilihat dari hasil perhitungan nilai korelasi pada siklus pertama antara pre test terhadap ujian harian pertama sebesar 0,827 dengan nilai uji t sebesar 8,333, dan siklus kedua antara post test terhadap ujian harian kedua sebesar 0,943 dengan nilai uji-t sebesar 16,075. Penggunaan kartu Persilangan Genetika Trihibrida (tiga sifat beda) sebagai media pembelajaran Biologi ini, dapat meningkatkan aktivitas siswa kelas XII Madrasah Aliyah Negeri Binjai tahun pelajaran 2019/2020 pada pelajaran Biologi tentang Persilangan Genetika Trihibrida (tiga sifat beda), hal ini dapat dilihat dari kehadiran siswa pada saat dilakukannya kegiatan penelitian tindakan kelas (PTK), dari 90\% siklus pertama meningkat menjadi 95\% dan $100 \%$ siklus kedua.
\end{abstract}

Kata Kunci : Kartu Persilangan Genetika Trihibrida Sebagai Media Pembelajaran Biologi, Hasil Belajar, Aktivitas

\section{PENDAHULUAN}

Perkembangan dunia dewasa ini, terutama perkembangan sains dan teknologi melaju dengan dengan sangat pesat. Hal ini menuntut sumber daya manusia setiap Negara yang handal dan mampu berkompetisi secara global. Kompetisi akan menjadi prinsip hidup yang baru dalam suatu masyarakat karena dunia yang 
terbuka, bersaing untuk mengejar kualitas dan keunggulan. Untuk menyesuaikan perkembangan tersebut peningkatan sumber daya manusia merupakan syarat mutlak untuk ditingkatkan melalui jalur pendidikan. Berangkat dari keyakinan bahwa masa depan bangsa ditentukan oleh kualitas sumber daya manusia, maka peranan sistem pendidikan nasional dalam kehidupan suatu bangsa menjadi sangat dominan. Oleh sebab itu, pendidikan harus selalu ditata agar benar-benar dapat menjadi wahana bagi pembangunan sumber daya manusia yang berkualitas.

Perkembangan suatu dunia pendidikan menuntut seorang pendidik atau guru untuk berkompetisi dalam program pembelajaran di kelas, sehingga berusaha membuat berbagai macam metode dalam mengajar. Kenyataan hasil observasi menunjukkan pembelajaran di sekolah khususnya pembelajaran Biologi hingga kini masih berpusat pada guru. Guru lebih mengutamakan metode ceramah dan cenderung mendominasi dalam pembelajaran sehingga siswa cenderung pasif, kurang termotivasi dan tidak terjadi interaksi yang baik dalam pembelajaran. Hal ini dikarenakan ceramah merupakan metode mengajar yang paling disukai oleh para pengajar. Agar metode ceramah yang dibawakan guru tidak membosankan perhatian siswa, maka guru perlu mengembangkan metode ini dengan menggunakan metode kartu persilangan genetika trihibrida sebagai media pembelajaran Biologi.
Berdasarkan wawancara dengan guru Biologi Madrasah Aliyah Negeri Binjai, keaktifan siswa di kelas masih rendah dan hasil belajar Biologi juga masih kurang memuaskan terutama pada materi genetika terutama trihibrida. Hal ini dapat dilihat dari rata-rata hasil belajar Biologi pada materi genetika terutama trihibrida tahun pelajaran 2019/2020 lalu siswa kelas XII Madrasah Aliyah Negeri Binjai yakni 80 dan belum mencapai kriteria ketuntasan maksimal untuk materi genetika terutama trihibrida yaitu 85. Kondisi yang seperti ini tentunya sangat tidak diharapkan dalam proses belajar mengajar. Oleh karenanya di kelas XII Madrasah Aliyah Negeri Binjai tahun pelajaran 2019/2020 ini penulis berusaha membuat penelitian tindakan kelas dengan menggunakan metode Kartu Genetika Trihibrida pada mata pelajaran Biologi akan dijadikan sebagai media pembelajaran Biologi.

Tujuan yang diharapkan adalah untuk mengetahui Penggunaan Kartu Persilangan Genetika Trihibrida Sebagai Media Pembelajaran Biologi Dapat Meningkatkan Hasil Belajar dan Aktivitas Siswa Kelas XII Madrasah Aliyah Negeri Binjai Tahun Pelajaran 2019/2020.

\section{METODE PENELITIAN}

Kegiatan Penelitian Tindakan Kelas (PTK) ini dilakukan di kelas XII Madrasah Aliyah Negeri Binjai tahun pelajaran 2019/2020, yang beralamat di jalan Pekan Baru No.1A Kelurahan Rambung Barat Binjai, dengan jumlah 34 siswa, siswa laki-laki 20 orang dan 
siswa perempuan 14 orang yang diambil secara acak ditiap-tiap kelas XII. Pelaksanaan penelitian ini dilaksanakan selama tiga bulan tahun 2019/2020, dan terdiri dari dua siklus.

Pelaksanaan pada siklus pertama dengan langkah-langkah sebagai berikut:

Perencanaan pertama, guru mempersiap kan RPP dan bahan ajar yang berkaitan dengan materi tentang Persilangan Genetika. Sistem kegiatan belajar mengajar pada siklus pertama ini menggunakan metode ceramah, yaitu guru menerangkan materi dan siswa memperhatikan penjelas an dari guru. Materi yang diberikan ke siswa pertama kali tentang genetika pada percobaan monohibrida tanaman berbatang tinggi dengan tanaman berbatang pendek.

Tindakan pertama, untuk memudahkan guru dalam menjelaskan materi tersebut, maka guru mempersiapkan kelompok diskusi sebanyak jumlah siswa, masingmasing siswa mendapat satu tugas yang bertuliskan penanya, penjawab, pengkritik, dan tanggapan terhadap kritik. Pada percobaan monohibrida tanaman berbatang tinggi dengan tanaman berbatang pendek ini, dibuat suatu tabel sebagai berikut:
Tabel 1. Macam Genotip dan Fenotip persilangan $\mathrm{Tt}$ (Tinggi) dengan $\mathrm{Tt}$ (Tinggi)

\begin{tabular}{c|c|c}
\hline $\begin{array}{c}\text { Macam } \\
\text { Genotip }\end{array}$ & $\begin{array}{c}\text { Macam } \\
\text { Fenotip }\end{array}$ & $\begin{array}{c}\text { Perbandingan } \\
\text { Fenotip }\end{array}$ \\
\hline $1 \mathrm{TT}$ & Tinggi & 3 \\
$2 \mathrm{Tt}$ & Tinggi & \\
\hline $1 \mathrm{tt}$ & Pendek & 1 \\
\hline
\end{tabular}

Dengan papan catur sebagai berikut :

Tabel 2. Papan Catur Hasil Perkawinan Silang

\begin{tabular}{c|c|c}
\hline & $\mathrm{T}$ & $\mathrm{t}$ \\
\hline $\mathrm{T}$ & $\mathrm{TT}$ & $\mathrm{Tt}$ \\
\hline $\mathrm{t}$ & $\mathrm{Tt}$ & $\mathrm{tt}$ \\
\hline
\end{tabular}

Siswa mencatat contoh perkawinan silang pada materi genetika yang telah dijelaskan oleh guru.

Observasi pertama, Observasi dilakukan oleh observer (pengamat) yaitu guru sebagai peneliti dan teman sejawat sebagai pendamping memperhatikan apa dan bagaimana siswa melakukan aktivitasnya disaat pada percobaan monohibrida tanaman berbatang tinggi dengan tanaman berbatang pendek, dengan tujuan untuk melihat dan menilai aktivitas siswa selama pembelajaran.

Refleksi (Reflection) pertama, pada tahap refleksi ini dilakukan analisis hasil belajar (pre test), analisis hasil observasi aktivitas siswa dalam pembelajaran, dan mengkaji materi genetika pertama tentang percobaan monohibrida tanaman berbatang tinggi dengan tanaman berbatang pendek, 
yang akan dilanjutkan ke materi genetika berikutnya, yang akan dilakukan pada siklus kedua.

Pelaksanaan

penelitian

berikutnya pada siklus kedua dilakukan beberapa rincian sebagai berikut :

Perencanaan kedua, pada pertemuan berikutnya guru bersikap memberikan motivasi dan menjelaskan cara penggunaan pembuatan kartu persilangan genetika pada percobaan dihibrida tanaman berbatang tinggi berbunga ungu disilangkan dengan tanaman berbatang pendek berbunga putih, dan trihibrida, dengan rincian sebagai berikut:

Tabel 3. Macam Genotip dan Fenotip Persilangan TU (Tinggi ungu) Dengan tu (Tinggi ungu)

\begin{tabular}{l|c|c}
\hline $\begin{array}{c}\text { Macam } \\
\text { Genotip }\end{array}$ & $\begin{array}{c}\text { Macam } \\
\text { Fenotip }\end{array}$ & $\begin{array}{c}\text { Perbandingan } \\
\text { Fenotip }\end{array}$ \\
\hline 1 TTUU & Tinggi Ungu & \\
2 TTUu & $\begin{array}{c}\text { Tinggi Ungu } \\
\text { Tinggi Ungu } \\
2 \text { TtUU }\end{array}$ & 9 \\
4 TtUu & Tinggi Ungu & \\
\hline 1 ttUU & Pendek Ungu & 3 \\
2 ttUu & Pendek Ungu & \\
\hline 1 TTuu & Tinggi Putih & 3 \\
2 Ttuu & Tinggi Putih & \\
\hline 1 ttuu & Pendek Putih & 1 \\
\hline
\end{tabular}

Tabel 4. Papan Catur Hasil Perkawinan Silang

\begin{tabular}{c|c|c|c|c}
\hline & $\mathrm{TU}$ & $\mathrm{Tu}$ & $\mathrm{tU}$ & $\mathrm{tu}$ \\
\hline $\mathrm{TU}$ & $\mathrm{TTU}$ & $\mathrm{TTU}$ & $\mathrm{TtU}$ & $\mathrm{TtU}$ \\
& $\mathrm{U}$ & $\mathrm{u}$ & $\mathrm{U}$ & $\mathrm{u}$ \\
\hline $\mathrm{Tu}$ & $\mathrm{TTUu}$ & $\mathrm{TTuu}$ & $\mathrm{TtUu}$ & $\mathrm{Ttuu}$ \\
\hline $\mathrm{tU}$ & $\mathrm{TtUU}$ & $\mathrm{TtUu}$ & $\mathrm{ttUU}$ & $\mathrm{ttUu}$ \\
\hline $\mathrm{tu}$ & $\mathrm{TtUu}$ & $\mathrm{Ttuu}$ & $\mathrm{ttUu}$ & $\mathrm{ttuu}$ \\
\hline
\end{tabular}

Berdasarkan tabel di atas adalah persilangan antara tanaman berbatang tinggi berbunga ungu disilangkan dengan tanaman berbatang pendek berbunga putih dengan perbandingan sebagai berikut:

$9: 3: 3: 1 \quad$ Berikutnya mencoba mengadakan perkawinan silang dengan tiga sifat beda (trihibrida) yaitu perkawinan silang antara tanaman berbatang Tinggi berbunga Ungu berbuah Bulat (TTUUBB) disilangkan dengan tanaman berbatang Pendek berbunga Putih berbuah Kisut (ttuubb), yang akan dilakukan pada langkah-langkah selanjutnya.

Tindakan kedua, guru membimbing siswa menjelaskan cara membuat kartu genetika, serta cara penggunaannya sebagai berikut: mencoba mengadakan perkawinan silang dengan tiga sifat beda (trihibrida) yaitu perkawinan silang antara tanaman berbatang Tinggi berbunga Ungu berbuah Bulat (TTUUBB) disilangkan dengan tanaman berbatang Pendek berbunga Putih berbuah Kisut (ttuubb). Hasil perkawinan silangnya adalah Tinggi Ungu Bulat sebanyak 27, Tinggi Putih Bulat sebanyak 9, Tinggi Ungu Kisut sebanyak 9, Pendek Ungu Bulat sebanyak 9, Tinggi Putih Kisut sebanyak 3, Pendek Unggu Kisut sebanyak 3, Pendek Putih Bulat sebanyak 3, Pendek Putih Kisut sebanyak 1, dengan perbandingan ; 27 $: 9: 9: 9: 3: 3: 3: 1$. 
Observasi/Pengamatan kedua, untuk mengetahui sejauhmana guru, temen sejawat, dan siswa dapat mengamati tindakan yang telah dilakukan di siklus kedua ini, sebagai berikut: Mengamati, meliputi; Siswa bersama guru mendiskusi kan hasil pengamatan dan kesimpulan dengan menjawab pertanyaan untuk didiskusikan. Siswa mengidentifikasi beberapa perkawinan silang untuk monohibrida, dihibrida dan trihibrida. Menanya, Dengan memberikan gambar perkawinan silang untuk monohibrida, dihibrida dan trihibrida. Guru menjelaskan materi genetika tentang perkawinan silang untuk monohibrida, dihibrida dan trihibrida. Setiap kelompok yang telah diberikan kartu genetika trihibrida tersebut diajarkan cara memainkannya. Guru menjelaskan cara bermain kartu genetika trihibrida kepada semua siswa dan para siswa diberikan kesempatan bertanya. Mengeksplorasikan, setelah beberapa siswa diberi kesempatan bertanya dan dijawab oleh guru biologi, maka siswa diberi sesempatan untuk mengeksplorasikan gambaran tentang perkawinan silang untuk monohibrida, dihibrida dan trihibrida. Mengasosiasikan, siswa pada tiap-tiap kelompok diberi satu set kartu genetika trihibrida yang telah disiapkan oleh guru dan langsung diajarkan cara bermainnya. Mengkomunikasikan, bagi tiap-tiap kelom pok yang berhasil memainkannya dengan waktu yang telah ditetapkan, siswa diberi kesempatan untuk mengeluarkan pendapat nya tentang media bermain kartu genetika trihibrida ini. Dan siswa menyimpulkan dan menjelaskan tentang hal-hal yang belum diketahui. Selanjutnya guru memberikan evaluasi setelah diadakannya permainan kartu genetika trihibrida ini.

Refleksi (Reflection) kedua, hasil obserrvasi yang telah dilakukan oleh guru bersama-sama siswa selama proses pem belajaran akan diadakan pengamatan tentang kegiatan siswa yang meliputi : (1) sikap siswa yang memperhatikan penjelasan guru, (2) bertanya tentang materi yang belum dimengerti, (3) bertanya bagaimana cara bermain kartu genetika trihibrida (4) aktif dalam diskusi dan bermain kartu genetika trihibrida, (5) menulis dan mencatan temen sejawat dalam keaktifan saat bermain kartu genetika trihibrida, (6) meminta penjelasan ulang pada setiap konsep dan cara bermainnya, (7) menyampaikan ide atau pendapat, (8) membaca buku atau LKS.

\section{HASIL PENELITIAN DAN PEMBAHASAN}

Persiapan yang dilakukan oleh seorang guru Biologi untuk mengadakan penelitian tindakan kelas di kelas XII Madrasah Aliyah Negeri Binjai ini adalah membuat kartu genetika trihibrida (persilangan tiga sifat beda), sebagai berikut : Satu set kartu ini jumlahnya harus 64 lembar, untuk itu kita perlu membuat daftar yang terdiri dari 8 baris dan 8 kolom berarti ada 64 kotak (hasil persilangan 
Fauziah : Penggunaan Kartu Persilangan ...

tiga sifat beda). Berikut ini contoh pembuatan kartu dengan kompetensi dasarnya : hasil perkawinan silang untuk tiga sifat beda pada tumbuhan. Dan Indikatornya : memahami simbol yang dihasilkan dari perkawinan silang dan menterjemahkannya ke dalam istilah sebenarnya.

Hasil perkawinan silang ini akan dibuat ke bentuk kartu genetika sebagai salah satu media pembelajaran biologi yang bertujuan belajar sambil bermain dan belajar itu menyenangkan. Dari contoh dan analisis perkawinan silang di atas dapat dibuat tabel untuk kemungkinan fenotip, genotip, rasio fenotip, dan jumlah gamet secara matematisnya. Selanjutnya dibuat bentuk tabel papan catur dari hasil persilangan genetika untuk tiga sifat beda (trihibrida) antara tanaman berbatang Tinggi berbunga Ungu berbuah Bulat (TTUUBB) disilangkan dengan tanaman berbatang Pendek berbunga Putih berbuah Kisut (ttuubb), sebagai berikut :

Tabel 5. Papan catur perkawinan silang antara tanaman berbatang Tinggi berbunga Ungu berbuah Bulat (TTUUBB) dengan tanaman berbatang Pendek berbunga Putih berbuah Kisut (ttuubb)

\begin{tabular}{|c|c|c|c|c|c|c|c|c|}
\hline 8 & TUB & TuB & TUb & tUB & Tub & tUb & tuB & tub \\
\hline TUB & $\begin{array}{l}1 \\
\text { TTUUBB }\end{array}$ & $\begin{array}{l}2 \\
\text { TTUuBB }\end{array}$ & $\begin{array}{l}3 \\
\text { TTUUBb }\end{array}$ & $\begin{array}{l}4 \\
\text { TtUUBB }\end{array}$ & $\begin{array}{l}5 \\
\text { TTUuBb }\end{array}$ & $\begin{array}{l}6 \\
\text { TtUUBb }\end{array}$ & $\begin{array}{l}7 \\
\text { TtUuBB }\end{array}$ & $\begin{array}{l}8 \\
\text { TtUuBb }\end{array}$ \\
\hline TuB & $\begin{array}{l}9 \\
\text { TTUuBB }\end{array}$ & $\begin{array}{l}10 \\
\text { TTuuBB }\end{array}$ & $\begin{array}{l}11 \\
\text { TTUuBb }\end{array}$ & $\begin{array}{l}12 \\
\text { TtUuBB }\end{array}$ & $\begin{array}{l}13 \\
\text { TTuuBb }\end{array}$ & $\begin{array}{l}14 \\
\text { TtUuBb }\end{array}$ & $\begin{array}{l}15 \\
\text { TtuuBB }\end{array}$ & $\begin{array}{l}16 \\
\text { TtuuBb }\end{array}$ \\
\hline TUb & $\begin{array}{l}17 \\
\text { TTUUBb }\end{array}$ & $\begin{array}{l}18 \\
\text { TTUuBb }\end{array}$ & $\begin{array}{l}19 \\
\text { TTUUbb }\end{array}$ & $\begin{array}{l}20 \\
\text { TtUUBb }\end{array}$ & $\begin{array}{l}21 \\
\text { TTUubb }\end{array}$ & $\begin{array}{l}22 \\
\text { TtUUbb }\end{array}$ & $\begin{array}{l}23 \\
\mathrm{TtUuBb}\end{array}$ & $\begin{array}{l}24 \\
\text { TtUubb }\end{array}$ \\
\hline tUB & $\begin{array}{l}25 \\
\text { TtUUBB }\end{array}$ & $\begin{array}{l}26 \\
\text { TtUuBB }\end{array}$ & $\begin{array}{l}27 \\
\text { TtUUBb }\end{array}$ & $\begin{array}{l}28 \\
\mathrm{ttUUBB}\end{array}$ & $\begin{array}{l}29 \\
\text { TtUuBb }\end{array}$ & $\begin{array}{l}30 \\
\mathrm{ttUUBb}\end{array}$ & $\begin{array}{l}31 \\
\mathrm{ttUuBB}\end{array}$ & $\begin{array}{l}32 \\
\mathrm{ttUuBb}\end{array}$ \\
\hline Tub & $\begin{array}{l}33 \\
\text { TTUuBb }\end{array}$ & $\begin{array}{l}34 \\
\text { TTuuBb }\end{array}$ & $\begin{array}{l}35 \\
\text { TTUubb }\end{array}$ & $\begin{array}{l}36 \\
\text { TtUuBb }\end{array}$ & $\begin{array}{l}37 \\
\text { TTuubb }\end{array}$ & $\begin{array}{l}38 \\
\text { TtUubb }\end{array}$ & $\begin{array}{l}39 \\
\text { TtuuBb }\end{array}$ & $\begin{array}{l}40 \\
\text { Ttuubb }\end{array}$ \\
\hline tUb & $\begin{array}{l}41 \\
\text { TtUUBb }\end{array}$ & $\begin{array}{l}42 \\
\text { TtUuBb }\end{array}$ & $\begin{array}{l}43 \\
\text { TtUUbb }\end{array}$ & $\begin{array}{l}44 \\
\mathrm{ttUUBb}\end{array}$ & $\begin{array}{l}45 \\
\text { TtUubb }\end{array}$ & $\begin{array}{l}46 \\
\mathrm{ttUUbb}\end{array}$ & $\begin{array}{l}47 \\
\mathrm{ttUuBb}\end{array}$ & $\begin{array}{l}48 \\
\text { ttUubb }\end{array}$ \\
\hline tub & $\begin{array}{l}57 \\
\mathrm{TtUuBb}\end{array}$ & $\begin{array}{l}58 \\
\text { TtuuBb }\end{array}$ & $\begin{array}{l}59 \\
\text { TtUubb }\end{array}$ & $\begin{array}{l}60 \\
\mathrm{ttUuBb}\end{array}$ & $\begin{array}{l}61 \\
\text { Ttuubb }\end{array}$ & $\begin{array}{l}62 \\
\text { ttUubb }\end{array}$ & $\begin{array}{l}63 \\
\text { ttuuBb }\end{array}$ & $\begin{array}{l}64 \\
\text { Ttuubb }\end{array}$ \\
\hline
\end{tabular}

Berikut Cara pembuatan tabelnya: buat tabel 9x9 artinya terdiri dari 9 baris dan 9 kolom. Pada baris pertama kolom pertama dibuat simbol genetik jantan dan betina, berikut pada baris pertama kolom 2 sampai 9 diisi dengan TUB kolom ke 2, TuB kolom ke 3, TUb kolom ke 4, tUB kolom ke 5, Tub kolom ke 6, tUb kolom ke 7, tuB kolom ke 8, tub kolom ke 9. Dan pada baris kedua sampai baris ke-9 diisi dengan TUB baris ke 2, TuB baris ke 3, TUb baris ke 4 , tUB baris ke 5, Tub baris ke 6 , tUb baris ke 7 , tuB baris ke 8 , tub baris ke 9 .

\section{Pembahasan}

Awal pertama kegiatan penelitian tindakan kelas (PTK) ini adalah guru menjelaskan pada siswa 
materi tentang genetika, yang akan dilakukan perkawinan persilangan dengan satu sifat beda (monohibrida), dua sifat beda (dihibrida), dan tiga sifat beda (trihibrida).

Selanjutnya, siswa yang sudah dibagi menjadi beberapa kelompok diskusi dipersilahkan untuk menulis ke depan mewakili kelompoknya bagaimana cara percobaan perkawinan silang genetika tersebut. Perwakilan yang sudah paham tentang materi genetika, dipersilahkan untuk berdiskusi bersama teman sekelompoknya. Hal ini dapat dilihat dari gambar berikut ini:

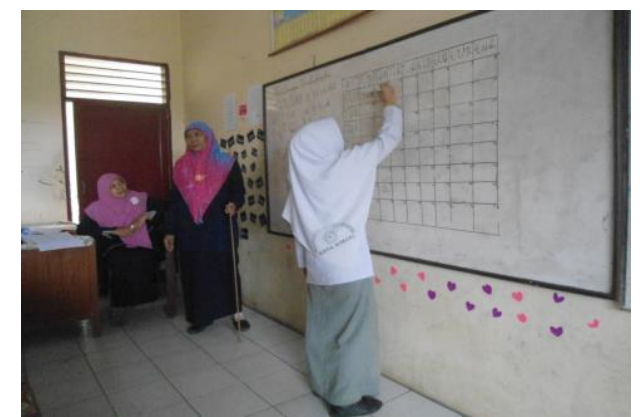

Hasil perkawinan silang tiga sifat beda (trihibrida) yang telah diperoleh siswa dapat dilihat pada gambar berikut ini:

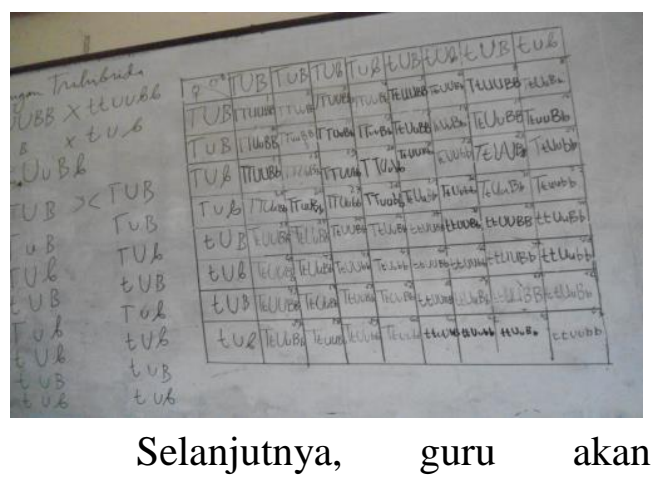

membimbing siswa untuk membuat kartu genetika tentang perkawinan silang tiga sifat beda (trihibrida) dengan ditulis di karton, lalu digunting sesuai dengan ukuran yang sama, dihubungkan berdasarkaan tabel yang ada, dan dicoba untuk dimainkan secara kelompok. Agar kartu terlihat bagus dan rapi, maka dibuat dengan komputer dan dicetak dengan rapi, yang akhirnya cara permainan kartu tersebut dapat dilihat pada gambar berikut:

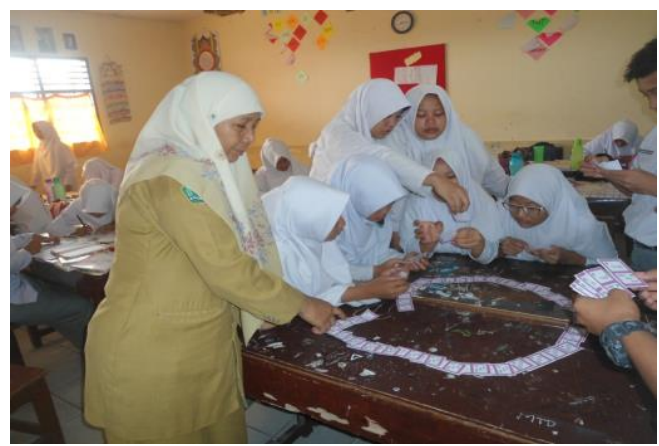

Cara bermain kartu persilangan genetika trihibrida sebagai berikut ; permainan ini dimainkan oleh 2, 3, 4, 6 atau 8 orang pemain, dengan cara yaitu:

- Bagikan kartu genetika yang khusus dibuat untuk permainan ini, sebanyak 4 atau 6 kartu untuk masing-masing pemain.

- Pemain pertama meletakkan sebuah kartu di meja (undilah siapa yang jadi pemain pertama).

- Atau kartu pertama diambil dari sisa kartu yang ada.

- Undilah siapa yang jadi pemain pertama

- Dengan urutan sesuai arah jarum jam para pemain menjatuhkan satu kartu pada setiap gilirannya.

- Nilai kartu yang dipasangkan (dijatuhkan) disesuaikan dengan nilai kartu yang ada (yang 
Fauziah : Penggunaan Kartu Persilangan ...

dijatuhkan) sampai pemain tidak memiliki kartu lagi.

- Pemasangan kartu berdasarkan simbol atau lambang genotipe yang disepakati dengan arti istilah fenotipe yang sebenarnya.

- Jika pemain tidak bisa "jalan" maka ia kehilangan satu giliran dan harus mencangkul atau mengmbil kartu lagi dari sisa kartu yang ada sampai menemukan kartu yang diinginkan (sesuai).

- Pemenangnya ialah yang pertama-tama dapat menghabiskan kartunya.

- Pemenang diberikan hadiah berupa nilai dari guru yang bersangkutan.
Cara bermainnya:
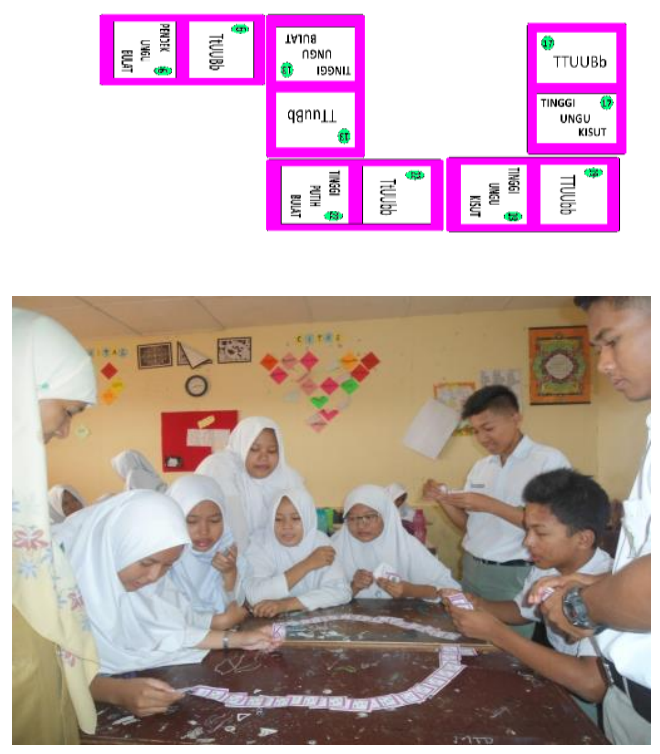

Hasil permainan ini dinilai oleh guru yang bersifat kelompok, maupun individu atau perorang, yang dapat dilihat pada tabel berikut ini:

Tabel 6. Hasil Penelitian Tindakan Kelas (PTK) Penggunaan Kartu Persilangan Genetika Trihibrida Sebagai Media Pembelajaran Biologi Dapat Meningkatkan Hasil Belajar dan Aktivitas Siswa Kelas XII MAN Binjai

\begin{tabular}{ccccccccccc}
\hline $\mathrm{z}$ & $\mathrm{X} 1$ & $\mathrm{X} 1 . \mathrm{X}$ & $\mathrm{Y} 1$ & $\mathrm{Y} 1 . \mathrm{Y}$ & $\mathrm{X} 1 . \mathrm{Y}$ & $\mathrm{X} 2$ & $\mathrm{X} 2 . \mathrm{X}$ & $\mathrm{Y} 2$ & $\mathrm{Y} 2 . \mathrm{Y}$ & $\mathrm{X} 2 . \mathrm{Y}$ \\
& & 1 & & 1 & 1 & & 2 & & 2 & 2 \\
\hline 1 & 86 & 7396 & 88 & 7744 & 7568 & 90 & 8100 & 92 & 8464 & 8280 \\
\hline 2 & 86 & 7396 & 88 & 7744 & 7568 & 90 & 8100 & 92 & 8464 & 8280 \\
\hline 3 & 87 & 7569 & 88 & 7744 & 7656 & 90 & 8100 & 92 & 8464 & 8280 \\
\hline 4 & 88 & 7744 & 87 & 7569 & 7656 & 89 & 7921 & 91 & 8281 & 8099 \\
\hline 5 & 90 & 8100 & 90 & 8100 & 8100 & 92 & 8464 & 94 & 8836 & 8648 \\
\hline 6 & 85 & 7225 & 87 & 7569 & 7395 & 89 & 7921 & 91 & 8281 & 8099 \\
\hline 7 & 88 & 7744 & 89 & 7921 & 7832 & 92 & 8464 & 94 & 8836 & 8648 \\
\hline 8 & 90 & 8100 & 91 & 8281 & 8190 & 95 & 9025 & 97 & 9409 & 9215 \\
\hline 9 & 85 & 7225 & 87 & 7569 & 7395 & 90 & 8100 & 92 & 8464 & 8280 \\
\hline 10 & 86 & 7396 & 88 & 7744 & 7568 & 90 & 8100 & 92 & 8464 & 8280 \\
\hline 11 & 82 & 6724 & 86 & 7396 & 7052 & 88 & 7744 & 90 & 8100 & 7920 \\
\hline 12 & 86 & 7396 & 88 & 7744 & 7568 & 90 & 8100 & 92 & 8464 & 8280 \\
\hline 13 & 90 & 8100 & 89 & 7921 & 8010 & 93 & 8649 & 95 & 9025 & 8835 \\
\hline 14 & 88 & 7744 & 90 & 8100 & 7920 & 94 & 8836 & 96 & 9216 & 9024 \\
\hline 15 & 89 & 7921 & 89 & 7921 & 7921 & 92 & 8464 & 94 & 8836 & 8648 \\
\hline 16 & 82 & 6724 & 85 & 7225 & 6970 & 88 & 7744 & 90 & 8100 & 7920 \\
\hline
\end{tabular}


SCHOOL EDUCATION JOURNAL VOLUME 11 NO. 1 JUNI 2021

\begin{tabular}{ccccccccccc}
\hline 17 & 87 & 7569 & 88 & 7744 & 7656 & 90 & 8100 & 92 & 8464 & 8280 \\
\hline 18 & 90 & 8100 & 92 & 8464 & 8280 & 95 & 9025 & 97 & 9409 & 9215 \\
\hline 19 & 88 & 7744 & 90 & 8100 & 7920 & 93 & 8649 & 95 & 9025 & 8835 \\
\hline 20 & 87 & 7569 & 88 & 7744 & 7656 & 90 & 8100 & 92 & 8464 & 8280 \\
\hline 21 & 84 & 7056 & 87 & 7569 & 7308 & 89 & 7921 & 91 & 8281 & 8099 \\
\hline 22 & 87 & 7569 & 89 & 7921 & 7743 & 92 & 8464 & 94 & 8836 & 8648 \\
\hline 23 & 91 & 8281 & 91 & 8281 & 8281 & 94 & 8836 & 96 & 9216 & 9024 \\
\hline 24 & 88 & 7744 & 89 & 7921 & 7832 & 92 & 8464 & 94 & 8836 & 8648 \\
\hline 25 & 87 & 7569 & 88 & 7744 & 7656 & 90 & 8100 & 92 & 8464 & 8280 \\
\hline 26 & 87 & 7569 & 87 & 7569 & 7569 & 89 & 7921 & 90 & 8100 & 8010 \\
\hline 27 & 89 & 7921 & 89 & 7921 & 7921 & 92 & 8464 & 93 & 8649 & 8556 \\
\hline 28 & 84 & 7056 & 86 & 7396 & 7224 & 88 & 7744 & 90 & 8100 & 7920 \\
\hline 29 & 85 & 7225 & 88 & 7744 & 7480 & 90 & 8100 & 92 & 8464 & 8280 \\
\hline 30 & 84 & 7056 & 87 & 7569 & 7308 & 89 & 7921 & 90 & 8100 & 8010 \\
\hline 31 & 87 & 7569 & 90 & 8100 & 7830 & 92 & 8464 & 94 & 8836 & 8648 \\
\hline 32 & 92 & 8464 & 93 & 8649 & 8556 & 95 & 9025 & 96 & 9216 & 9120 \\
\hline 33 & 90 & 8100 & 93 & 8649 & 8370 & 93 & 8649 & 94 & 8836 & 8742 \\
\hline 34 & 85 & 7225 & 88 & 7744 & 7480 & 89 & 7921 & 90 & 8100 & 8010 \\
\hline & 296 & 2578 & 301 & 2671 & 2624 & 309 & 2817 & 315 & 2931 & 2873 \\
& 0 & 90 & 3 & 21 & 39 & 4 & 00 & 6 & 00 & 41 \\
\hline & 87, & & 88, & $\mathrm{r}=0,827$ & 91 & & 92, & $\mathrm{r}=0,9433$ \\
& 1 & & 6 & & & & & 8 & & \\
\hline & 87, & & 88, & $\mathrm{t}=8,333$ & 91 & & 92, & $\mathrm{t}=16,075$ \\
& 1 & & 6 & & & & & 8 & & \\
\hline & & & & & & & & & & \\
\hline
\end{tabular}

Berdasarkan diagram batang di atas menunjukkan peningkatan yaitu: rata-rata siklus pertama ujian pre test sebesar 87,1 dan ujian harian pertama sebesar 88,6 dan pada siklus kedua ujian post test sebesar 91 dan ujian harian kedua sebesar 92,8 sementara nilai kriteria ketuntasan minimal (KKM sebesar 85). Hal ini menunjukkan peningkatan nilai ratarata hasil belajar siswa pada pelajaran Biologi materi tentang genetika.

Begitu juga nilai korelasi pada siklus pertama antara ujian pre test ter hadap ujian harian pertama sebesar 0,827 dengan nilai uji t sebesar 8,333 , dan pada siklus kedua nilai korelasi antara ujian post test terhadap ujian harian kedua sebesar 0,943 dengan nilai uji t sebesar 16,075 . Ini artinya menunjukkan korelasi yang sangat signifikansi.

Berikutnya, aktivitas siswa juga meningkat, hal ini dapat dilihat dari kehadiran siswa selama mengikuti kegiatan penelitian selama tiga bulan, yang tertera pada diagram batang berikut: 


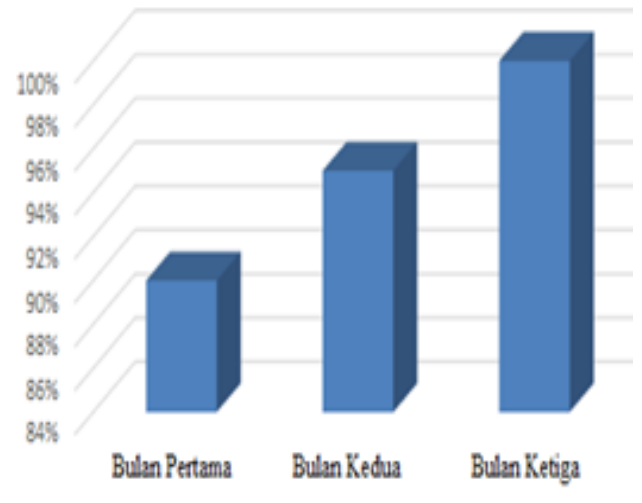

Diagram 1. Hasil Kehadiran Siswa

Berdasarkan diagram batang di atas terdapat peningkatan absensi kehadiran siswa pada siklus pertama kehadiran sekitar $90 \%$, dan pada siklus kedua kehadiran sekitar 95\%, dan meningkat menjadi $100 \%$.

\section{SIMPULAN}

Kesimpulan yang sangat diharap kan dalam kegiatan penelitian tindakan kelas (PTK) ini adalah penggunaan kartu persilangan Genetika Trihibrida sebagai media pembelajaran Biologi dapat meningkatkan hasil belajar dan aktivitas siswa kelas XII Madrasah Aliyah Negeri Binjai Tahun Pelajaran 2019/2020, hal ini dapat dilihat dari hasil perhitungan diperoleh nilai korelasi antara ujian pre test terhadap ujian harian pertama sebesar 0,827 dengan nilai uji t sebesar 8,333 pada siklus pertama, dan nilai korelasi antara ujian post test terhadap ujian harian kedua sebesar 0,943 dengan nilai uji t sebesar 16,075 pada siklus kedua, sementara kehadiran siswa pada siklus pertama 90\%, dan pada siklus kedua $95 \%$ meningkat menjadi $100 \%$.

\section{DAFTAR RUJUKAN}

Ahmadi, A., dan Supriyono, W. 1993. Psikologi Belajar. Jakarta: Raja Grafindo Persada.

Applin D. 2002. Key Science Bioligy. Canada: Cheltenham Nelson Thonnes.

Arif Priadi. 2010. BIOLOGI SMA Kelas XII. Jakarta: Yudhistira.

Departemen Pendidikan Nasional. 2006. Standar Kompetensi dan Kompetensi Dasar Biologi, SMA-MA, Jakarta, Depdiknas. Yayat Ibayati. 2000. Penuntun Belajar Biologi 3. Bandung: Ganeca Exact.

Yusuf M. 2001. Genetika I, Struktur dan Ekspresi Gen. Bogor: Sagung Seto. 